\title{
Nelfinavir inhibits proliferation and induces DNA damage in thyroid cancer cells
}

\author{
Kirk Jensen', Athanasios Bikas², Aneeta Patel1, Yevgeniya Kushchayeva3, \\ John Costello1, Dennis McDaniel4, Kenneth Burman5 and Vasyl Vasko'
}

\begin{abstract}
1Department of Pediatrics, Uniformed Services University of the Health Sciences, Bethesda, Maryland, USA ${ }^{2}$ Department of Internal Medicine, Georgetown University Hospital MedStar, Washington Hospital Center Internal Medicine Residency Program, Washington, District of Columbia, USA ${ }^{3}$ National Institutes of Health, NIDDK, Bethesda, Maryland, USA

4 Uniformed Services University of the Health Sciences, Biomedical Instrumentation Center, Bethesda, Maryland, USA ${ }^{5}$ MedStar Washington Hospital Center, Endocrinology, Washington, District of Columbia, USA
\end{abstract}

\author{
Correspondence \\ should be addressed \\ to $\mathrm{K}$ Jensen \\ Email \\ kirk.jensen@usuhs.edu
}

\begin{abstract}
The HIV protease inhibitor Nelfinavir (NFV) inhibits PI3K/AKT and MAPK/ERK signaling pathways, emerging targets in thyroid cancers. We examined the effects of NFV on cancer cells that derived from follicular (FTC), papillary (PTC) and anaplastic (ATC) thyroid cancers. NFV (1-20 $\mu \mathrm{M})$ was tested in FTC133, BCPAP and SW1736 cell lines. The effects of NFV on cell proliferation were determined in vitro using real-time microscopy and by flow cytometry. DNA damage, apoptotic cell death and expression of molecular markers of epithelial-mesenchymal transition (EMT) were determined by Western blot and real-time PCR. Real-time imaging demonstrated that NFV $(10 \mu \mathrm{M})$ increased the time required for the cell passage through the phases of cell cycle and induced DNA fragmentation. Growth inhibitory effects of NFV were associated with the accumulation of cells in G0/G1 phase, downregulation of cyclin D1 and cyclin-dependent kinase 4 (CDK4). NFV also induced the expression of $\gamma \mathrm{H} 2 \mathrm{AX}$ and p53BP1 indicating DNA damage. Treatment with NFV $(20 \mu \mathrm{M})$ resulted in caspase-3 cleavage in all examined cells. NFV $(20 \mu \mathrm{M})$ decreased the levels of total and p-AKT in PTEN-deficient FTC133 cells. NFV had no significant effects on total ERK and p-ERK in BRAF-positive BCPAP and SW1736 cells. NFV had no effects on the expression of EMT markers (Twist, Vimentin, $\mathrm{E}$ - and $\mathrm{N}$-Cadherin), but inhibited the migration and decreased the abilities of thyroid cancer cells to survive in non-adherent conditions. We conclude that NFV inhibits proliferation and induces DNA damage in thyroid cancer cell lines. Our in vitro data suggest that NFV has a potential to become a new thyroid cancer therapeutic agent.
\end{abstract}

\section{Key Words \\ - thyroid \\ - carcinoma}




\section{Introduction}

Thyroid cancer is the most common endocrine malignancy (Hundahl et al. 1998) and is also increasing at the fastest incidence rate of any malignancy (Morris et al. 2016). Patients with differentiated thyroid cancer have an excellent prognosis (Sherman 2003, Cabanillas et al. 2016); however, when thyroid cancer patients present with distant metastases at the time of surgery, the overall 10-year survival rate is only $40 \%$ (Muresan et al. 2008). Analysis of clinicopathologic features predictive of diseasespecific mortality revealed that, in addition to distant metastases, gross tumor extension beyond the thyroid and poorly differentiated histology are closely linked to deaths in non-anaplastic follicular cell-derived thyroid carcinomas (Xu et al. 2016). Both recurrences and death from PTC can occur more than 30 years after being treated, and development of recurrent disease significantly worsens prognosis (Grogan et al. 2013). In patients stratified according to American Thyroid Association risk categories (low, intermediate or high), persistent structural disease or recurrence was identified in 3\% of the low-risk, $21 \%$ of the intermediate-risk and $68 \%$ of the high-risk patients (Tuttle et al. 2010). The mortality of patients with a recurrence has been shown as high as 38-69\% (Samaan et al. 1983, Tubiana et al. 1985). Loss of differentiation is generally associated with a poor prognosis, and patients with I131-positive metastases have demonstrated a $60 \%$ 10-year survival in comparison with $10 \%$ for patients with $\mathrm{I}^{131}$-negative metastases (Durante et al. 2006). Anaplastic thyroid cancer (ATC) is a rare form of thyroid cancer, but is associated with a poor prognosis because of rapid tumor growth and poor response to conventional treatments (Cabanillas et al. 2016).

Thus, patients with metastatic and recurrent thyroid cancers, as well as tumors that lose the ability to trap I131, are obvious candidates for alternative therapeutic approaches.

Potential strategies for targeted therapy of thyroid cancer include inhibition of angiogenesis, inhibition of aberrant intracellular signaling in the MAPK and PI3K/AKT/mTOR pathways, radio-immunotherapy and re-differentiation agents (Liebner \& Shah 2011). In addition, repositioning of well-established FDA-approved drugs for the treatment of cancer emerged as an alternative drug development strategy (Zhang et al. 2012, KluboGwiezdzinska et al. 2013, Kushchayeva et al. 2014a). For example, metformin, a well-known medication for the management of diabetes, demonstrated inhibitory effects on cancer cell growth in various experimental models of cancers. The retrospective analysis of clinicopathological characteristics in diabetic patients with thyroid cancer showed that tumor size was significantly smaller in metformin-treated compared to the non-metformintreated groups. A multivariate model revealed that treatment with metformin increased the likelihood of a complete response and increased progression-free survival in thyroid cancer patients with diabetes (KluboGwiezdzinska et al. 2013). Several other medications are currently under investigation for their repositioning in the treatment of cancer patients.

Nelfinavir (NFV) is an HIV protease inhibitor that is currently being repositioned for cancer therapy. It is being evaluated in oncologic clinical trials for pancreatic cancer, non-small-cell lung cancer, liposarcoma and glioblastoma multiforme (Brunner et al. 2008, Pan et al. 2012, Rengan et al. 2012, Hill et al. 2016). Clinical observations have demonstrated that the toxicities associated with HIV protease inhibitors are similar to those observed with inhibition of the phosphoinositide 3-kinase (PI3K)/ AKT pathway, a major anti-apoptotic signaling cascade in cancer. Subsequent experimental in vitro and in vivo studies demonstrated the inhibitory effects of NFV on PI3K/AKT signaling pathway in a variety of human cancers (Pore et al. 2006, Yang et al. 2006, Gills et al. 2007, Shim et al. 2012).

We have reported previously that NFV inhibited the viability of medullary thyroid cancer cells, decreased the level of RET protein and blocked the activation of RET downstream targets (phosphorylated ERK, phosphorylated AKT and p70S6K/pS6) (Kushchayeva et al. 2014b). These findings suggested that NFV could be effective against differentiated thyroid cancer cells with mutations in the PI3K/AKT pathway, as well as in tumors with activating mutations in MAPK-BRAF-ERK signaling.

In this study, we used thyroid cancer cells with different mutations and examined their response to treatment with NFV using real-time microscopy. We determined the effects of NFV on thyroid cancer cell growth, activation of thyroid oncogene-inducible signaling pathways, DNA damage and apoptosis. We also examined the effects of NFV on the migration of thyroid cancer cells in vitro.

\section{Materials and methods}

\section{Thyroid cancer cells culture and reagents}

Human thyroid cancer cell lines derived from follicular (FTC133), papillary (BCPAP) and anaplastic (SW1736)

Published by Bioscientifica Ltd 
thyroid cancers were obtained from Dr Motoyasu Saji (The Ohio State University) with permission from the researchers who originally established the cell lines. All cell lines had been tested and authenticated by DNA analysis to be of thyroid origin (Schweppe et al. 2008). These cell lines express common thyroid oncogenes including BRAF V600E (BCPAP and SW1736) or have loss of PTEN expression (FTC133). In our laboratory, we confirmed the mutation status of BCPAP and examined the expression of PTEN by Western blot in FTC133 cells.

Cancer cells were propagated in conventional RPMI1640 medium (Invitrogen) supplemented with $10 \%$ of fetal bovine serum (FBS), $100 \mathrm{U} / \mathrm{mL}$ penicillin and $100 \mathrm{mg} / \mathrm{mL}$ streptomycin in a humidified $5 \% \mathrm{CO}_{2}$ incubator. The cells were subcultured with $0.5 \%$ trypsin and $0.02 \%$ EDTA (Sigma-Aldrich) when the cell confluency reached $80 \%$. All experiments were performed using thyroid cancer cell lines that had been passaged fewer than 25 times.

The HIV protease inhibitor Nelfinavir was obtained from Sigma-Aldrich. Nelfinavir (NFV) was dissolved in dimethyl sulfoxide (DMSO) and kept as a stock solution at a concentration of $5 \mathrm{mM}$.

\section{Live cell imaging and cell viability assays}

For real-time microscopy, thyroid cancer cells were grown on eight-well Lab-Tek chamber slides at 50-60\% confluency and treated with NFV $(10 \mu \mathrm{M})$ for $24 \mathrm{~h}$. Live cell imaging was performed using the Leica AF6000 Time Lapse Imaging System. Images were taken every $5 \mathrm{~min}$. Sequential images were compiled into a time lapse video format.

Cell proliferation rate was determined by cell counting using the Vi-CELL Cell Viability Analyzer from Beckman Coulter (Fullerton, CA, USA), and cell viability was determined by Alamar blue assay. Dead cells were detected using propidium iodine staining. All experiments were repeated at least three times, and the average values of representative experiments are reported.

\section{Flow cytometry}

Flow cytometery analysis of cells stained with propidium iodide (PI) was performed on a BD LSRII flow cytometer. A $488 \mathrm{~nm}$ laser was used for the dye excitation; 595 long pass and 610/20 band pass filters were used for emission detection. Single cells were gated using forward scatter height and area parameters. The single cell population gate was confirmed by using area and width parameters of PI channel. The calculation of different phases of cell cycle was done using ModFit LT analysis software.

\section{Cell migration and anoikis assays}

Cell migration was examined by using a Boyden chamber (8- $\mu \mathrm{m}$ pore size), and cells were stained by using a DiffQuick staining kit (Dade Behring, Newark, DE, USA). All migration experiments were performed on at least three occasions in duplicate.

For anoikis experiments, cells were cultured in lowadherent cell culture conditions (poly-HEMA-treated plates). In low-adherent conditions, cell viability was determined by the evaluation of mitochondrial membrane potential with a fluorogenic lipophilic cation (JC-1; Cayman Chemical Company).

\section{RNA extraction and quantitative RT-PCR}

Total RNA was isolated from thyroid cancer cells using the RNeasy Mini Kit (Qiagen) according to the manufacturer's protocol. SYBR green-based qPCR master mixes were obtained from Qiagen. Quantitative RT-PCR screening of thyroid-specific genes (NKX2-1, SLC5A5 (sodium iodide symporter) and $T G$ (thyroglobulin)) as well as genes with an established role in the regulation of epithelial-tomesenchymal transition (TWIST1, VIM (vimentin), CDH1 (E-Cadherin), $\mathrm{CDH} 2$ (N-Cadherin)) was performed using commercially available primers and probes from Qiagen.

\section{Protein extraction and Western blot analysis}

Thyroid cancer cells were incubated with ice-cold cell lysis buffer, scraped, centrifuged and the supernatant was stored at $-80^{\circ} \mathrm{C}$. Twenty-five micrograms of total protein lysate were suspended in reduced SDS sample buffer, and the lysates were subjected to SDS-PAGE (4-12\%). The separated proteins were transferred to a nitrocellulose membrane (Invitrogen) by electrophoretic blotting. Membranes were incubated overnight with primary antibody against BRAF V600 (Spring Bioscience Corporation, Pleasanton, CA, USA); vimentin and b-actin (Sigma-Aldrich), p-AKT1/2/3 (Ser473), total AKT, p-ERK1/2, total ERK, retinoblastoma tumor suppressor protein (Rb), p-Rb, CDK4, cleaved caspase 3 and cleaved PARP (Cell Signaling Technology); $\mathrm{N}$-Cadherin, Connexin-43, Cyclin D1, $\gamma \mathrm{H} 2 \mathrm{AX}$ and p53BP1 (Santa Cruz Biotechnology). Detection of proteins was performed using the Li-Cor Odyssey imaging system (LI-COR Biosciences, Lincoln, NE, USA). 


\section{Immunostaining}

For immunostaining, thyroid cancer cells were cultured overnight on eight-chambered SuperCell Culture Slides (Thermo Fisher Scientific) and then fixed in formalin for 15 min. After washing with PBS, cells were incubated for $1 \mathrm{~h}$ at room temperature with anti-p53BP1 or anti- $\gamma \mathrm{H} 2 \mathrm{AX}$ antibody. Slides were then incubated at room temperature for $1 \mathrm{~h}$ with species-specific Alexa 488-conjugated secondary antibody.

\section{Results}

\section{Assessment of thyroid cancer cells' response to Nelfinavir by real-time microscopy}

To determine the morphological changes in thyroid cancer during exposure to NFV $(10 \mu \mathrm{M})$, we performed real-time microscopy for $24 \mathrm{~h}$. Non-treated thyroid cancer cells were characterized by constant motion (Supplementary
Videos 1, 2 and 3; see section on supplementary data given at the end of this article). Collective cell migration and single cell movements were observed in FTC133, SW1736 as well as in BCPAP cells. Cell count at 6, 12, 18 and $24 \mathrm{~h}$ showed that the number of cells almost doubled at $24 \mathrm{~h}$ in all examined cell lines. Live imaging revealed distinct morphological changes in cells undergoing division. These changes included cell-substrate adhesion remodeling ( $15 \mathrm{~min})$, resulting in cell rounding ( $\sim 15 \mathrm{~min})$, cellular elongation with formation of the central furrow ( $30 \mathrm{~min})$, the separation of two daughter cells ( 15 min) and re-establishing adherence to substrate ( $\sim 5 \mathrm{~min}$ ). Representative images of the phases of BCPAP single cell division are presented in Fig. 1A. In FTC133, SW1736 and BCPAP, the entire process of cell division occurred within $120 \pm 15,145 \pm 20$ and $100 \pm 25$ min, respectively.

Treatment with NFV was associated initially with the inhibition of cell growth. As an example, in BCPAP cells, the time required for cell-substrate adhesion
A

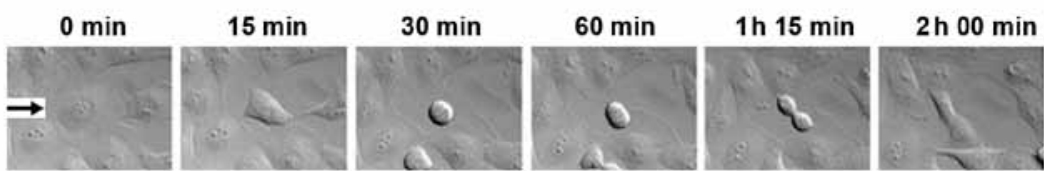

B

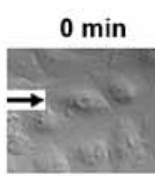

$30 \mathrm{~min}$
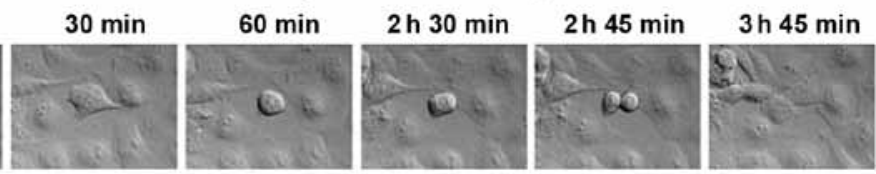

C

BCPAP cells (NFV for 6-24 h)
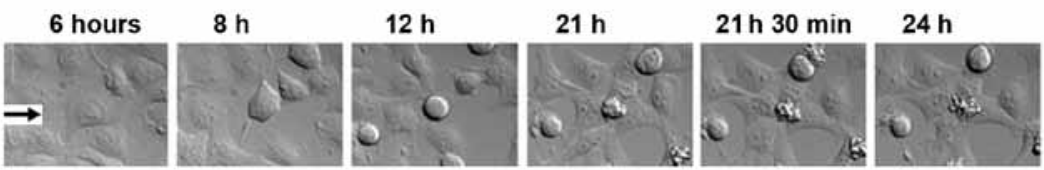

D FTC133 cells

BCPAP cells
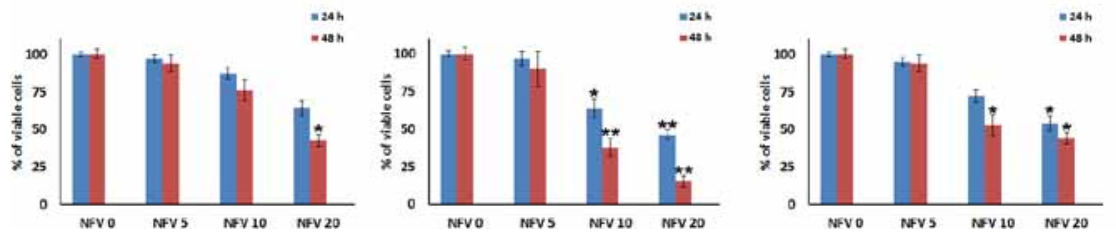

\section{Figure 1}

Time lapse microscopy and effect of Nelfinavir upon cell viability. (A, B, and C) Images from time lapse microscopy of BCPAP cells - representative of all cell lines. (A) Control cells in RPMI media. Sequential images of a single cell (arrow) passing through visibly discernible stages of cell division. Time course follows: $15 \mathrm{~min}$ for cell-substrate adhesion remodeling, $15 \mathrm{~min}$ for cell rounding, $30 \mathrm{~min}$ for elongation of cell with formation of central furrow, $15 \mathrm{~min}$ for separation of daughter cells and approximately $45 \mathrm{~min}$ for re-adhesion of each daughter cell to the substrate. (B) NFV inhibits cell proliferation. Sequential images of a single cell (arrow) passing through stages of cell division. Time course as follows: $30 \mathrm{~min}$ for cell-substrate adhesion remodeling, $30 \mathrm{~min}$ for cell rounding, $90 \mathrm{~min}$ for elongation of cell with formation of central furrow, $15 \mathrm{~min}$ for separation of daughter cells, and approximately $60 \mathrm{~min}$ for re-adhesion of each daughter cell to the substrate. (C) Extended exposure to NFV leads to cell death. Sequential images of a single cell (arrow) demonstrating mitotic arrest and apoptosis. At $6 \mathrm{~h}$ of incubation with NFV, a morphologically normal adherent thyroid cancer cell is indicated. After the cell-substrate remodeling phase, a round-shaped cell remains for hours without formation of the central furrow. Development of membrane blebs precedes complete destruction of the cell. (D) Treatment with NFV resulted in a dosedependent decrease in the number of viable cells in FTC133, BCPAP and SW1736 cells. Growth inhibitory effects were more prominent after thyroid cancer cells exposure to NFV for $48 \mathrm{~h}$ ( $* P$ value $<0.05$ and ${ }^{*} P$ value $<0.01$ ). BCPAP cells were the most sensitive to NFV exposure. These results are derived from three separate experiments. Error bars demonstrate the consistent effect. 
remodeling, cell rounding, formation of the central furrow, the separation of two daughter cells and re-adhesion was 30, 30, 90, 15 and $60 \mathrm{~min}$, respectively (Fig. 1B). The time for the entire process of cell division was twice longer in NFV-treated BCPAP cells as compared to that in control cells. These effects of NFV were also observed in FTC133 and SW1736 cells. Dynamic imaging revealed that NFV affected the time required for cells to passage through the phases of cell cycle in all examined cell lines (Supplementary Videos 4, 5 and 6).

With extended exposure to NFV, thyroid cancer cells progressively lose their ability to form the central furrow and exhibited morphological features suggesting mitotic arrest (round, non-dividing cells for up to $4 \mathrm{~h}$ ). NFVtreated cells were not able to proceed with mitotic exit and underwent apoptosis (Fig. 1C and Supplementary Videos 4, 5 and 6).

To confirm these observations, we assessed the viability of thyroid cancer cells by performing Alamar blue assay after treatment with increasing concentration of NFV for 48h. As demonstrated in Fig. 1D, NFV inhibited thyroid cancer cell growth in a dose- and a time-dependent manner.

To demonstrate the effects of NFV on cell cycle progression, we performed flow cytometry analysis and the results are presented in Table 1 and in Supplementary Fig. 1 (see section on supplementary data given at the end of this article). In all examined cell lines, NFV increased the proportion of cells in G0/G1 phase with the reduction
Table 1 FACS analysis of thyroid cancer cell lines treated with Nelfinavir.

\begin{tabular}{|c|c|c|c|}
\hline \multirow[b]{2}{*}{ Cell lines } & \multicolumn{3}{|c|}{$\begin{array}{l}\% \text { of cells in different phases of the cell } \\
\text { cycle phases }\end{array}$} \\
\hline & G0/G1 & $\mathrm{S}$ & $\mathrm{G} 2 / \mathrm{M}$ \\
\hline 133 control & 45.1 & 37.9 & 17.0 \\
\hline $133 \mathrm{NFV} 10 \mu \mathrm{M}$ & 45.0 & 37.7 & 17.3 \\
\hline $133 \mathrm{NFV} 20 \mu \mathrm{M}$ & 61.9 & 22.1 & 16.0 \\
\hline BCPAP control & 47.3 & 36.9 & 15.8 \\
\hline BCPAP NFV $10 \mu \mathrm{M}$ & 67.1 & 23.0 & 9.9 \\
\hline BCPAP NFV $20 \mu \mathrm{M}$ & 77.7 & 12.1 & 10.2 \\
\hline SW1736 control & 56.0 & 31.9 & 12.1 \\
\hline SW1736 NFV $10 \mu \mathrm{M}$ & 55.9 & 31.9 & 12.2 \\
\hline SW1736 NFV $20 \mu \mathrm{M}$ & 67.8 & 21.7 & 10.5 \\
\hline
\end{tabular}

of cells in S phase of the cell cycle. The most prominent effects were observed in BCPAP cells.

Nelfinavir inhibits the expression of cell cycle regulators, induces DNA damage and apoptosis

Real-time microscopy suggested that the reduction of cell number after treatment with NFV could be the result of either cell cycle arrest or cell death. To address this question, we performed Western blot analysis with antibodies directed against cell cycle regulators (cyclin D1, CDK4 and $\mathrm{Rb})$. In thyroid cancer cells, NFV decreased the expression of Cyclin D1 and CDK4 in a dose-dependent manner (Fig. 2A). The level of total $\mathrm{Rb}$ was significantly higher in
A

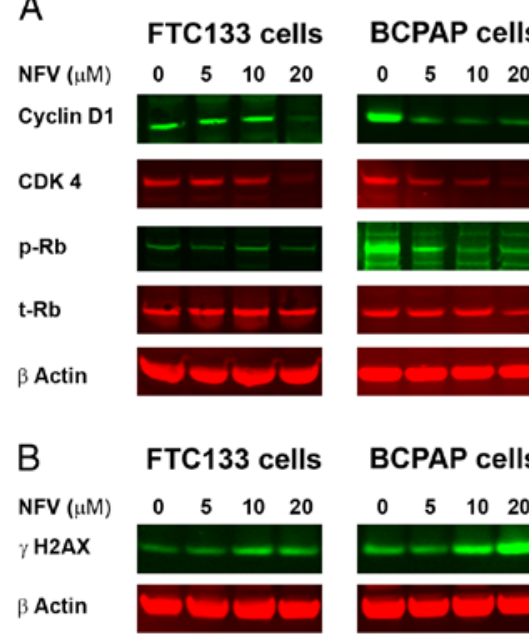

\section{SW1736 cells} $\begin{array}{llll}0 & 5 & 10 & 20\end{array}$
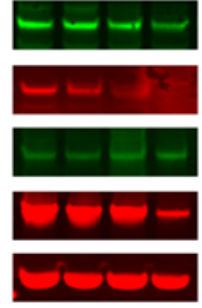

SW1736 cells

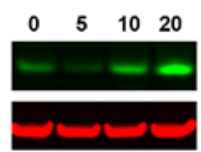

C

Control
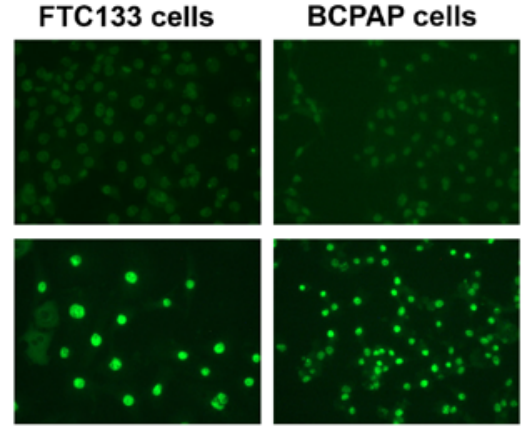

FTC133 cells

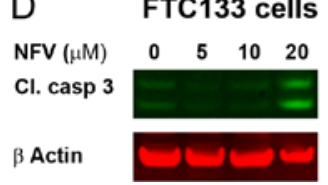

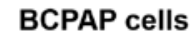

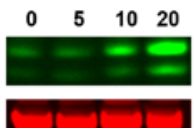

SW1736 cells
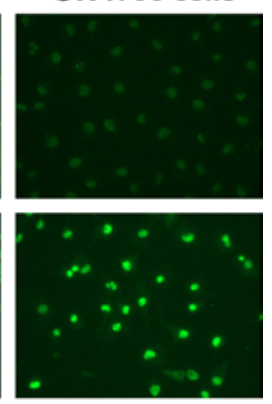

SW1736 cells

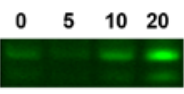

Figure 2

Nelfinavir affects regulators of cell cycle, DNA damage and apoptosis in thyroid cancer cells. (A) Western blot demonstrates that protein levels of Cyclin $\mathrm{D} 1, \mathrm{CDK} 4$ and phospho-Rb are decreased after treatment with NFV for $24 \mathrm{~h}$. Total Rb protein level is unchanged after treatment with $\mathrm{NFV}(10 \mu \mathrm{M})$, but decreased after exposure to NFV at a concentration of $20 \mu \mathrm{M}$. (B) Western blot demonstrates accumulation of $\gamma \mathrm{H} 2 \mathrm{AX}$ protein after treatment with NVF for 24h. (C) p53BP1 is present in foci localized in the nuclei of NFV-treated cells. (D) Dose-dependent effect upon expression of cleaved caspase 3. In BCPAP and SW1736 cells, cleavage of caspase 3 is evident after $24 \mathrm{~h}$ of treatment with NFV $10 \mu \mathrm{M}$. In FTC133 cells, NFV $10 \mu \mathrm{M}$ did not induce cleavage of caspase 3 , but treatment with NFV $20 \mu \mathrm{M}$ did. 
FTC133 cells

NFV $(\mu \mathrm{M}) \quad 0 \quad 1020$
p-AKT
t-AKT
t-ERK
BRAF V600
B Actin

BCPAP cells

\begin{tabular}{l|ll} 
NFV $(\mu \mathrm{M})$ & 0 & $10 \quad 20$ \\
p-AKT & \\
t-AKT & \\
p-ERK & \\
t-ERK & \\
BRAF V600 & \\
\hline B Actin &
\end{tabular}

\section{SW1736 cells}

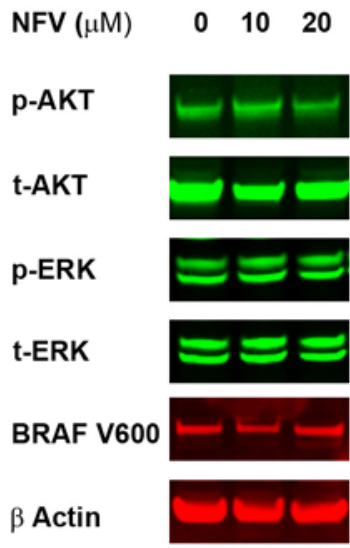

Figure 3

Nelfinavir's effects on cell signaling activation in thyroid cancer cells. (A) NFV inhibited AKT phosphorylation and decreased total AKT in FTC133 cells. The level of p-ERK was unchanged in all three cell lines. Mutant BRAF V600E is expressed in BCPAP and SW 1736 cells (not present in FTC133) and shows no significant changes in expression after exposure to NFV at both $10 \mu \mathrm{M}$ and $20 \mu \mathrm{M}$.
SW1736 cells as compared to FTC133 and BCPAP cells at baseline conditions. The highest level of phospho- $\mathrm{Rb}$ was detected in BCPAP cells. Nelfinavir $(10 \mu \mathrm{M})$ decreased the level of phospho- $\mathrm{Rb}$ without effects on total $\mathrm{Rb}$ in BCPAP cells. However, in BCPAP cells as wells as in FTC133 and SW1736 cells, the protein level of total Rb was decreased after exposure to NFV at concentration $20 \mu \mathrm{M}$.

Treatment with NFV induced DNA damage in FTC133, BCPAP and SW1736 cells. As demonstrated in Fig. 2B, the level of $\gamma \mathrm{H} 2 \mathrm{AX}$ expression was increased in NFV-treated thyroid cancer cell lines in a dose-dependent manner. Immunostaining with anti-p53BP1 demonstrated the presence of foci localized in the nuclei of NFV-treated cells, but not control cells (Fig. 2C).

PTC-derived (BCPAP) cells were more sensitive to NFV-inducible apoptosis as compared to FTC-derived cells (FTC133 cells) or ATC-derived cells (SW1736 cells). As demonstrated in Fig. 2D, treatment with NFV $10 \mu \mathrm{M}$ resulted in caspase 3 and PARP cleavage in BCPAP cells, but not in FTC133 or SW1736 cells. Induction of apoptosis was noted in all examined thyroid cancer cell lines after exposure to NFV at a concentration of $20 \mu \mathrm{M}$.

These results showed that at concentrations achievable clinically in patients, NFV affected the expression of genes controlling thyroid cancer cell growth and induce DNA damage.

\section{The effects of Nelfinavir on AKT and ERK signaling in thyroid cancer cells}

Growth inhibitory effects of NFV in various cancer cell lines were attributed to its ability to block HSP90 function and promote degradation of HSP90 client proteins. Because HSP90 is a binding partner for protein kinase B
(AKT) and contributes to activation of ERK, we examined the effects of NFV on these signaling proteins in thyroid cancer cells. NFV decreased the levels of total AKT with concomitant decline of AKT phosphorylation in FTC133 cells. NFV had no effects on the expression of total ERK and did not inhibit ERK phosphorylation in BCPAP and SW1736 cells (Fig. 3A).

We examined the effects of NFV on expression of the BRAF V600 mutant in BCPAP and SW1736 cells. Western blot analysis with anti-BRAF V600E showed its expression in BCPAP and SW1736 but not in FTC133 cells (Fig. 3B). Treatment with NFV at concentrations of $10 \mu \mathrm{M}$ and $20 \mu \mathrm{M}$ was not associated with downregulation of the BRAF V600E mutant in BCPAP and SW1736 cells.

These data suggest that cytotoxic effects of NFV on thyroid cancer cells were not mediated via inhibition of the thyroid oncogene-inducible signaling pathways.

The effect of NFV on expression of thyroid-specific genes and markers of epithelial-to-mesenchymal transition

To determine if NFV influences thyroid cancer cell differentiation, we examined the expression of thyroidspecific genes by RT-PCR. Treatment with increasing concentrations of NFV did not induce changes in mRNA levels of NKX2-1, SLC5A5 and TG. We also examined the expression of molecules controlling epithelial-tomesenchymal transition, which is critical for thyroid cancer cell migration and invasion. Expression of Twist, $\mathrm{N}$-Cadherin and Vimentin mRNA was not affected by NFV. Results of RT-PCR analysis were confirmed by Western blot with specific antibodies against Vimentin and N-Cadherin (Fig. 4A). 
A

FTC133 cells BCPAP cells SW1736 cells

\begin{tabular}{|c|c|c|c|}
\hline NFV $(\mu \mathrm{M})$ & $\begin{array}{lll}0 & 5 & 10\end{array}$ & $\begin{array}{lll}0 & 5 & 10\end{array}$ & $5 \quad 10$ \\
\hline Vimentin & & 5 & \\
\hline $\mathrm{N}$-Cadherin & $6=$ & -00 & 50 \\
\hline$\beta$ Actin & & se & 50 \\
\hline
\end{tabular}

B FTC133 cells

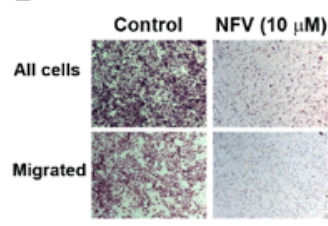

\section{BCPAP cells}

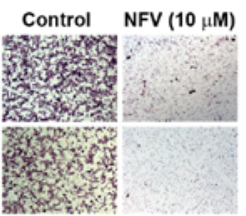

SW1736 cells Control NFV $(10 \mu \mathrm{M})$

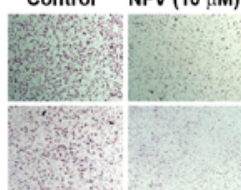

C

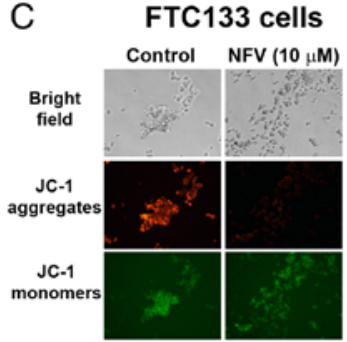

D

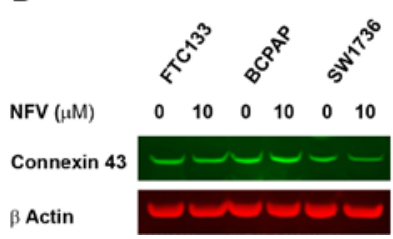

BCPAP cells

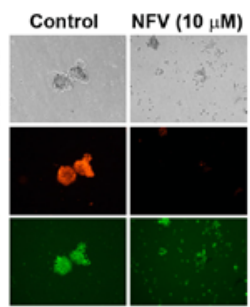

SW1736 cells

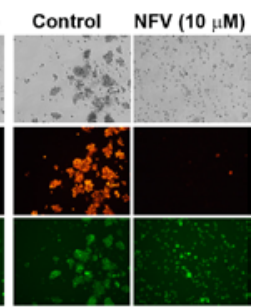

Non-adherent cells

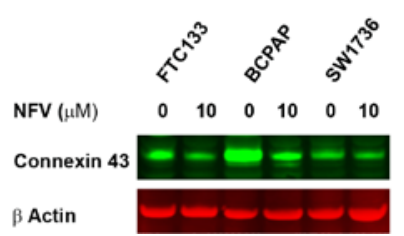

Figure 4

Nelfinavir's effects on migration and resistance to anoikis. (A) Western blot results for Vimentin and N-Cadherin show no change in FTC133, BCPAP or SW1736 cells after NFV treatment. (B) Migration assay: for FTC133, BCPAP and SW 1736 cells, more than $50 \%$ of control cells migrate in $24 \mathrm{~h}$; there is no migration of cells pre-treated with NFV $10 \mu \mathrm{M}$. (C) Cell culture in low-adherent conditions. Control cells coalesce into a spheroid structure with multiple cell-to-cell connections. Treatment with NFV led to loss of cell-to-cell contacts and was associated with cell death (anoikis). Bright field images show characteristic morphologic changes of anoikis in NFV-treated cells. Markedly diminished JC-1 aggregates in NFV-treated cells, indicating decreased cell viability. (D) Western blot results for Connexin-43 show minimal changes in adherent FTC133, BCPAP or SW1736 cells after NFV treatment; prominent inhibition of Connexin-43 by NFV in non-adherent cells.

We also examined the invasive ability of thyroid cancer cells by performing Boyden chamber migration assays. At baseline conditions, thyroid cancer cells were able to migrate through $8 \mu \mathrm{m}$ pore membrane; at $24 \mathrm{~h}$ after plating onto the top chamber, more than $50 \%$ of cells migrated and were detected at the bottom surface of the membrane (Fig. 4B). In contrast, thyroid cancer cells that were treated with NFV for $24 \mathrm{~h}$ were not able to adhere to the top surface of the membrane; subsequently, there were no cells located at the bottom surface of the membrane.

We also examined the effects of NFV on thyroid cancer cell resistance to anoikis (a form of apoptosis that is induced by loss of cell attachment to the extracellular matrix). As demonstrated in Fig. 4C, NFV prevented the formation of spheroid-like structures in non-adherent conditions. NFV-inducible loss of cell-to-cell contacts between thyroid cancer cells growing in non-adherent conditions was associated with loss of mitochondrial membrane potential and massive cell death.

We previously reported that Connexin-43-mediated activation of gap-junctional transport, which is important for thyroid cancer cell survival in non-adherent conditions. Therefore, we examined the effects of NFV on the expression of Connexin-43 in adherent and nonadherent thyroid cancer cell lines. Treatment with NFV $(10 \mu \mathrm{M})$ had minimal effects on Connexin-43 protein level in adherent thyroid cancer cells (Fig. 4D). Thyroid cancer cell adaptation to non-adherent conditions was associated with overexpression of Connexin-43. However, induction of Connexin-43 was significantly attenuated in cells that were treated with NFV (Fig. 4D). In nonadherent conditions, NFV decreased the protein level of Connexin- 43 by 32,76 and 29\%, respectively, in FTC133, BCPAP and SW1736 cells.

These results suggest that despite the negligible effects of NFV on the expression of mesenchymal markers, the invasive ability of thyroid cancer cells as well as their resistance to anoikis were significantly inhibited by NFV.

\section{Discussion}

The identification of new anti-cancer activities from existing, well-tolerated and effective medications represents an effective way to accelerate the translation of experimental findings into clinical application. In the present study, we examined the potential utility of NFV, a drug with well-known and tolerable side effects, for the treatment of thyroid cancer. We focused on the molecular mechanisms implicated in thyroid cancer cell response to NFV and we report several novel findings. First, we showed that NFV is toxic for thyroid cancer cells. Second, we demonstrated that the anti-cancer effects of NFV were associated with the inhibition of cell proliferation and 
induction of DNA damage in thyroid cancer cells. Third, we provided evidence that NFV inhibited migratory abilities and sensitized thyroid cancer cells to anoikis.

Success in repositioning NFV for the treatment of thyroid cancer patients will rely on the ability to induce cancer cell death with a clinically achievable dose of NFV. Individual NFV plasma concentrations have been found to behighlyvariablein HIV-infected persons. Pharmacokinetic studies in HIV patients using NFV (1250 mg twice-daily) reported trough plasma concentration ranging from 0.36 to $10.57 \mathrm{mg} / \mathrm{L}(0.5-18.6 \mu \mathrm{M}$; the geometric mean was $1.98 \mathrm{mg} / \mathrm{L}$ or $3.5 \mu \mathrm{M}$ ) (Pai \& Nahata 1999, Marzolini et al. 2001). In a more recent study in 39 patients being treated for pancreatic cancer with standard NFV dosing of $1250 \mathrm{mg}$ BID, trough concentrations were much less varied, ranging from $0.9 \mathrm{mg} / \mathrm{L}$ to $1.7 \mathrm{mg} / \mathrm{L}(1.6-3 \mu \mathrm{M})$; and peak concentrations ranged from $4.4 \mathrm{mg} / \mathrm{L}$ to $11.3 \mathrm{mg} / \mathrm{L}$ (7.7-20 $\mu \mathrm{M})$ (Kattel et al. 2015).

In this study, we examined the effects of various concentrations of NFV (1-20 $\mu \mathrm{M})$ on thyroid cancer cells growth in vitro.

We employed real-time microscopy for analysis of thyroid cancer cell response to the treatment with NFV. To our knowledge, this is the first report demonstrating real-time behavior of thyroid cancer cells treated with NFV in vitro. We found that growth of examined thyroid cancer cells was significantly affected by NFV in a timedependent manner.

In all examined thyroid cancer cell lines, we observed the prominent effects of NFV on cell division with morphological changes suggesting an aberrant transition through the $S$ phase of the cell cycle. These observations were confirmed by flow cytometry. By performing Western blot analysis, we demonstrated that NFV $(10 \mu \mathrm{M})$ inhibited the expression of genes controlling cell proliferation and induced DNA damage. Thyroid cancer cell exposure to NFV $(20 \mu \mathrm{M})$ induced apoptosis.

Our findings are consistent with previous reports demonstrating growth inhibitory and pro-apoptotic effects of NFV in breast, prostate and lung cancer cell lines (Gills et al. 2007, Shim et al. 2012). Similarly to results of our study, NFV induced cell cycle arrest via inhibition of cyclin-dependent kinase and concomitant dephosphorylation of retinoblastoma tumor suppressor in melanoma cell lines (Jiang et al. 2007). Our results in BCPAP cells are consistent with findings in melanoma cell lines demonstrating that initial $\mathrm{Rb}$ dephosphorylation followed by decrease in total $\mathrm{Rb}$ protein expression during extended exposure to NFV (Jiang et al. 2007).
It has been shown that NFV acts as an inhibitor of heat shock protein 90 (HSP90) signaling and induces degradation of HSP90 client proteins (da Rocha Dias et al. 2005, Whitesell \& Lindquist 2005); this activity depends on cancer cell oncogene mutation status (Shim et al. 2012). As PI3K, AKT and BRAF are substrates for the HSP90-mediated protein folding process, we examined the effects of NFV on activation of PI3K/AKT and MAPK/ ERK signaling pathways in PTEN-deficient FTC133 and BRAF-positive BCPAP and SW1736 cells.

Analysis of NFV-mediated effects on activation of signaling pathways in thyroid cancer cells showed that the NFV-inducible blockade of proliferation in BCPAP and SW1736 cells was not associated with changes in p-AKT. Growth inhibitory effects of NFV were less prominent in FTC133 cells; however, in this cell line, NFV inhibited total AKT and decreased AKT phosphorylation. Our observations are consistent with previously reported findings demonstrating that AKT-dependent and AKTindependent mechanisms are involved in cancer cell response to treatment with NFV. It has been demonstrated that inhibition of AKT signaling is a major antitumor mechanism of NFV in HER2-positive, but not in HER2negative breast cancer cells (Shim et al. 2012). In the same study, the author presented data indicating that inhibition of tumor growth under treatment with NFV occurred without significant changes in p-AKT, suggesting that mechanisms independent of AKT could play a role in the anti-cancer activities of NFV.

In our study, NFV did not decrease the protein level of the BRAF V600 mutant and did not inhibit activation of ERK in BCPAP cells. Previous work has shown that NFV may not inhibit p-ERK, but can profoundly sensitize BRAFand NRAS-mutant melanoma cells to MAPK pathway inhibitors (Smith et al. 2016). We are currently examining the efficacy of treatment with NFV in combination with clinically available inhibitors of the MAPK pathway in thyroid cancer cells.

NFV exhibits a wide spectrum of anti-cancer activities, such as induction of endoplasmic reticulum stress, autophagy (Bruning et al. 2009), induction of oxidative stress and ROS production (Ben-Romano et al. 2006). In addition, inhibition of mitochondrial membrane potential and a decrease in intracellular ATP concentration was demonstrated in cells treated with HIV protease inhibitors (Bociaga-Jasik et al. 2013). It is possible that differential effects of NFV on BCPAP, SW1736 and FTC133 cells were observed because of different basal metabolic activity in these examined cells. In our current research,

Published by Bioscientifica Ltd 
we are exploring the role of metabolic determinants in the thyroid cancer cell response to NFV.

Previously reported studies demonstrated that NFV increased the efficacy of radiotherapy via reduction of hypoxia and improved vascularization (Gupta et al. 2005). To determine the potential use of NFV as a re-differentiating agent, we examined the expression of genes controlling RAI uptake in thyroid cells. RT-PCR showed that NFV had no significant effect on expression of thyroid-specific genes, suggesting that NFV may have a limited utility in combination with radio-iodine treatment. We must also consider that the results of in vitro experiments do not always correlate with the tumor cell response to treatment in vivo. It is still possible that NFV-inducible changes in the tumor microenvironment could potentiate the efficacy of radiotherapy, and additional studies using animal model are needed to clarify this question.

Thyroid cancers are characterized by early metastatic spread, and epithelial-to-mesenchymal transition has been demonstrated in an animal model of thyroid cancer as well as in human thyroid cancers (Vasko et al. 2007, Knauf et al. 2011). NFV did not affect expression of markers of epithelial-to-mesenchymal transition; however, it did significantly decrease the migratory ability of thyroid cancer cells. We also performed anoikis experiments and showed that NFV inhibits thyroid cancer cell survival under non-adherent conditions. As resistance to anoikis is a major factor underlying the development of metastases, our data suggest that NFV could be effective as a suppressor of metastatic dissemination.

In summary, our findings provide evidence that NFV inhibits proliferation and induces DNA damage in thyroid cancer cells. NFV also inhibits thyroid cancer cell migration and sensitizes them to anoikis. On the basis of these findings, we propose that NFV, a commonly used and well-tolerated anti-HIV drug, has a potential to become a new thyroid cancer therapeutic agent.

\section{Supplementary data}

This is linked to the online version of the paper at http://dx.doi.org/10.1530/ ERC-16-0568.

\section{Declaration of interest}

The authors declare that there is no conflict of interest that could be perceived as prejudicing the impartiality of the research reported. The views presented in this manuscript are those of the authors; no endorsement by the Uniformed Services University of the Health Sciences or the Department of Defense has been given or should be inferred.

\section{Funding}

This research did not receive any specific grant from any funding agency in the public, commercial or not-for-profit sector.

\section{Acknowledgments}

The authors thank Dr Ildy Katona (Chair, Department of Pediatrics, Uniformed Services University of the Health Sciences) for her support of this project.

\section{References}

Ben-Romano R, Rudich A, Etzion S, Potashnik R, Kagan E, Greenbaum U \& Bashan N 2006 Nelfinavir induces adipocyte insulin resistance through the induction of oxidative stress: differential protective effect of antioxidant agents. Antiviral Therapy 11 1051-1060.

Bociaga-Jasik M, Polus A, Goralska J, Czech U, Gruca A, Sliwa A, Garlicki A, Mach T \& Dembinska-Kiec A 2013 Metabolic effects of the HIV protease inhibitor - saquinavir in differentiating human preadipocytes. Pharmacological Reports 65 937-950. (doi:10.1016/ S1734-1140(13)71075-2)

Bruning A, Burger P, Vogel M, Rahmeh M, Gingelmaiers A, Friese K, Lenhard M \& Burges A 2009 Nelfinavir induces the unfolded protein response in ovarian cancer cells, resulting in ER vacuolization, cell cycle retardation and apoptosis. Cancer Biology and Therapy $\mathbf{8}$ 226-232. (doi:10.4161/cbt.8.3.7339)

Brunner TB, Geiger M, Grabenbauer GG, Lang-Welzenbach M, Mantoni TS, Cavallaro A, Sauer R, Hohenberger W \& McKenna WG 2008 Phase I trial of the human immunodeficiency virus protease inhibitor nelfinavir and chemoradiation for locally advanced pancreatic cancer. Journal of Clinical Oncology 26 2699-2706. (doi:10.1200/JCO.2007.15.2355)

Cabanillas ME, McFadden DG \& Durante C 2016 Thyroid cancer. Lancet 388 2783-2795. (doi:10.1016/S0140-6736(16)30172-6)

da Rocha Dias S, Friedlos F, Light Y, Springer C, Workman P \& Marais R 2005 Activated B-RAF is an Hsp90 client protein that is targeted by the anticancer drug 17-allylamino-17-demethoxygeldanamycin. Cancer Research 65 10686-10691. (doi:10.1158/0008-5472.CAN-052632)

Durante C, Haddy N, Baudin E, Leboulleux S, Hartl D, Travagli JP, Caillou B, Ricard M, Lumbroso JD, De Vathaire F, et al. 2006 Longterm outcome of 444 patients with distant metastases from papillary and follicular thyroid carcinoma: benefits and limits of radioiodine therapy. Journal of Clinical Endocrinology and Metabolism 91 2892-2899. (doi:10.1210/jc.2005-2838)

Gills JJ, Lopiccolo J, Tsurutani J, Shoemaker RH, Best CJ, Abu-Asab MS, Borojerdi J, Warfel NA, Gardner ER, Danish M, et al. 2007 Nelfinavir, a lead HIV protease inhibitor, is a broad-spectrum, anticancer agent that induces endoplasmic reticulum stress, autophagy, and apoptosis in vitro and in vivo. Clinical Cancer Research 13 5183-5194. (doi:10.1158/1078-0432.CCR-07-0161)

Grogan RH, Kaplan SP, Cao H, Weiss RE, Degroot LJ, Simon CA, Embia OM, Angelos P, Kaplan EL \& Schechter RB 2013 A study of recurrence and death from papillary thyroid cancer with 27 years of median follow-up. Surgery 154 1436-1446; discussion 1446-1437. (doi:10.1016/j.surg.2013.07.008)

Gupta AK, Cerniglia GJ, Mick R, McKenna WG \& Muschel RJ 2005 HIV protease inhibitors block Akt signaling and radiosensitize tumor cells both in vitro and in vivo. Cancer Research 65 8256-8265. (doi:10.1158/0008-5472.CAN-05-1220)

Hill EJ, Roberts C, Franklin JM, Enescu M, West N, MacGregor TP, Chu KY, Boyle L, Blesing C, Wang LM, et al. 2016 Clinical trial of oral nelfinavir before and during radiation therapy for advanced 
rectal cancer. Clinical Cancer Research 22 1922-1931. (doi:10.1158/1078-0432.CCR-15-1489)

Hundahl SA, Fleming ID, Fremgen AM \& Menck HR 1998 A National Cancer Data Base report on 53,856 cases of thyroid carcinoma treated in the U.S., 1985-1995. Cancer 83 2638-2648. (doi:10.1002/ (SICI)1097-0142(19981215)83:12<2638::AID-CNCR31>.0.CO;2-1)

Jiang W, Mikochik PJ, Ra JH, Lei H, Flaherty KT, Winkler JD \& Spitz FR 2007 HIV protease inhibitor nelfinavir inhibits growth of human melanoma cells by induction of cell cycle arrest. Cancer Research $\mathbf{6 7}$ 1221-1227. (doi:10.1158/0008-5472.CAN-06-3377)

Kattel K, Evande R, Tan C, Mondal G, Grem JL \& Mahato RI 2015 Impact of CYP2C19 polymorphism on the pharmacokinetics of nelfinavir in patients with pancreatic cancer. British Journal of Clinical Pharmacology 80 267-275. (doi:10.1111/bcp.12620)

Klubo-Gwiezdzinska J, Costello J Jr, Patel A, Bauer A, Jensen K, Mete M, Burman KD, Wartofsky L \& Vasko V 2013 Treatment with metformin is associated with higher remission rate in diabetic patients with thyroid cancer. Journal of Clinical Endocrinology and Metabolism 98 3269-3279. (doi:10.1210/jc.2012-3799)

Knauf JA, Sartor MA, Medvedovic M, Lundsmith E, Ryder M, Salzano M Nikiforov YE, Giordano TJ, Ghossein RA \& Fagin JA 2011 Progression of BRAF-induced thyroid cancer is associated with epithelial-mesenchymal transition requiring concomitant MAP kinase and TGFbeta signaling. Oncogene 30 3153-3162. (doi:10.1038/ onc.2011.44)

Kushchayeva Y, Jensen K, Burman KD \& Vasko V 2014a Repositioning therapy for thyroid cancer: new insights on established medications. Endocrine-Related Cancer 21 R183-R194. (doi:10.1530/ ERC-13-0473)

Kushchayeva Y, Jensen K, Recupero A, Costello J, Patel A, KluboGwiezdzinska J, Boyle L, Burman K \& Vasko V 2014b The HIV protease inhibitor nelfinavir down-regulates RET signaling and induces apoptosis in medullary thyroid cancer cells. Journal of Clinical Endocrinology and Metabolism 99 E734-E745. (doi:10.1210/ jc.2013-3369)

Liebner DA \& Shah MH 2011 Thyroid cancer: pathogenesis and targeted therapy. Therapeutic Advances in Endocrinology and Metabolism 2 173-195. (doi:10.1177/2042018811419889)

Marzolini C, Buclin T, Decosterd LA, Biollaz J \& Telenti A 2001 Nelfinavir plasma levels under twice-daily and three-times-daily regimens: high interpatient and low intrapatient variability. Therapeutic Drug Monitoring 23 394-398. (doi:10.1097/00007691200108000-00012)

Morris LG, Tuttle RM \& Davies L 2016 Changing trends in the incidence of thyroid cancer in the United States. JAMA Otolaryngology: Head and Neck Surgery 142 709-711. (doi:10.1001/jamaoto.2016.0230)

Muresan MM, Olivier P, Leclere J, Sirveaux F, Brunaud L, Klein M, Zarnegar R \& Weryha G 2008 Bone metastases from differentiated thyroid carcinoma. Endocrine-Related Cancer 15 37-49. (doi:10.1677/ ERC-07-0229)

Pai VB \& Nahata MC 1999 Nelfinavir mesylate: a protease inhibitor. Annals of Pharmacotherapy 33 325-339. (doi:10.1345/aph.18089)

Pan J, Mott M, Xi B, Hepner E, Guan M, Fousek K, Magnusson R, Tinsley R, Valdes F, Frankel P, et al. 2012 Phase I study of nelfinavir in liposarcoma. Cancer Chemotherapy and Pharmacology 70 791-799. (doi:10.1007/s00280-012-1961-4)

Pore N, Gupta AK, Cerniglia GJ, Jiang Z, Bernhard EJ, Evans SM, Koch CJ, Hahn SM \& Maity A 2006 Nelfinavir down-regulates hypoxia-inducible factor 1alpha and VEGF expression and increases tumor oxygenation: implications for radiotherapy. Cancer Research 66 9252-9259. (doi:10.1158/0008-5472.CAN-06-1239)
Rengan R, Mick R, Pryma D, Rosen MA, Lin LL, Maity AM, Evans TL, Stevenson JP, Langer CJ, Kucharczuk J, et al. 2012 A phase I trial of the HIV protease inhibitor nelfinavir with concurrent chemoradiotherapy for unresectable stage IIIA/IIIB non-small cell lung cancer: a report of toxicities and clinical response. Journal of Thoracic Oncology 7 709-715. (doi:10.1097/jto.0b013e3182435aa6)

Samaan NA, Maheshwari YK, Nader S, Hill CS Jr, Schultz PN, Haynie TP, Hickey RC, Clark RL, Goepfert H, Ibanez ML, et al. 1983 Impact of therapy for differentiated carcinoma of the thyroid: an analysis of 706 cases. Journal of Clinical Endocrinology and Metabolism 56 1131-1138. (doi:10.1210/jcem-56-6-1131)

Schweppe RE, Klopper JP, Korch C, Pugazhenthi U, Benezra M, Knauf JA, Fagin JA, Marlow LA, Copland JA, Smallridge RC \& Haugen BR 2008 Deoxyribonucleic acid profiling analysis of 40 human thyroid cancer cell lines reveals cross-contamination resulting in cell line redundancy and misidentification. Journal of the Clinical Endocrinology and Metabolism 93 4331-4341. (doi:10.1210/jc.2008-1102)

Sherman SI 2003 Thyroid carcinoma. Lancet 361 501-511. (doi:10.1016/ S0140-6736(03)12488-9)

Shim JS, Rao R, Beebe K, Neckers L, Han I, Nahta R \& Liu JO 2012 Selective inhibition of HER2-positive breast cancer cells by the HIV protease inhibitor nelfinavir. Journal of the National Cancer Institute 104 1576-1590. (doi:10.1093/jnci/djs396)

Smith MP, Brunton H, Rowling EJ, Ferguson J, Arozarena I, Miskolczi Z, Lee JL, Girotti MR, Marais R, Levesque MP, et al. 2016 Inhibiting drivers of non-mutational drug tolerance is a salvage strategy for targeted melanoma therapy. Cancer Cell 29 270-284. (doi:10.1016/j. ccell.2016.02.003)

Tubiana M, Schlumberger M, Rougier P, Laplanche A, Benhamou E, Gardet P, Caillou B, Travagli JP \& Parmentier C 1985 Long-term results and prognostic factors in patients with differentiated thyroid carcinoma. Cancer 55 794-804. (doi:10.1002/10970142(19850215)55:4<794::AID-CNCR2820550418>3.0.CO;2-Z)

Tuttle RM, Tala H, Shah J, Leboeuf R, Ghossein R, Gonen M, Brokhin M, Omry G, Fagin JA \& Shaha A 2010 Estimating risk of recurrence in differentiated thyroid cancer after total thyroidectomy and radioactive iodine remnant ablation: using response to therapy variables to modify the initial risk estimates predicted by the new American Thyroid Association staging system. Thyroid 20 1341-1349. (doi:10.1089/thy.2010.0178)

Vasko V, Espinosa AV, Scouten W, He H, Auer H, Liyanarachchi S, Larin A, Savchenko V, Francis GL, de la Chapelle A, et al. 2007 Gene expression and functional evidence of epithelial-to-mesenchymal transition in papillary thyroid carcinoma invasion. PNAS $\mathbf{1 0 4}$ 2803-2808. (doi:10.1073/pnas.0610733104)

Whitesell L \& Lindquist SL 2005 HSP90 and the chaperoning of cancer. Nature Reviews Cancer 5 761-772. (doi:10.1038/nrc1716)

$\mathrm{Xu}$ B, Ibrahimpasic T, Wang L, Sabra MM, Migliacci JC, Tuttle RM, Ganly I \& Ghossein R 2016 Clinicopathologic features of fatal nonanaplastic follicular cell-derived thyroid carcinomas. Thyroid $\mathbf{2 6}$ 1588-1597. (doi:10.1089/thy.2016.0247)

Yang Y, Ikezoe T, Nishioka C, Bandobashi K, Takeuchi T, Adachi Y, Kobayashi M, Takeuchi S, Koeffler HP \& Taguchi H 2006 NFV, an HIV-1 protease inhibitor, induces growth arrest, reduced Akt signalling, apoptosis and docetaxel sensitisation in NSCLC cell lines. British Journal of Cancer 95 1653-1662. (doi:10.1038/sj.bjc.6603435)

Zhang L, He M, Zhang Y, Nilubol N, Shen M \& Kebebew E 2012 Quantitative high-throughput drug screening identifies novel classes of drugs with anticancer activity in thyroid cancer cells: opportunities for repurposing. Journal of Clinical Endocrinology and Metabolism 97 E319-E328. (doi:10.1210/jc.2011-2671)

Received in final form 27 December 2016

Accepted 30 January 2017

Accepted Preprint published online 30 January 2017 http://erc.endocrinology-journals.org

DOI: $10.1530 /$ ERC-16-0568
(C) 2017 Society for Endocrinology Printed in Great Britain 